\title{
Legal Judgment as a Philosophical Archetype
}

A Pragmatist Analysis of Three Theses

\section{Giovanni Tuzet}

\section{(2) OpenEdition}

Electronic version

URL: http://journals.openedition.org/ejpap/851

DOI: 10.4000/ejpap.851

ISSN: 2036-4091

\section{Publisher}

Associazione Pragma

Electronic reference

Giovanni Tuzet, «Legal Judgment as a Philosophical Archetype », European Journal of Pragmatism and American Philosophy [Online], III-2 | 2011, Online since 29 December 2011, connection on 19 April 2019. URL : http://journals.openedition.org/ejpap/851 ; DOI : 10.4000/ejpap.851

This text was automatically generated on 19 April 2019.

\section{c) () $९$}

Author retains copyright and grants the European Journal of Pragmatism and American Philosophy right of first publication with the work simultaneously licensed under a Creative Commons AttributionNonCommercial-NoDerivatives 4.0 International License. 


\title{
Legal Judgment as a Philosophical Archetype
}

\author{
A Pragmatist Analysis of Three Theses
}

\author{
Giovanni Tuzet
}

\section{AUTHOR'S NOTE}

The author wishes to thank two anonymous referees of this journal for their helpful comments and suggestions on a previous version of this work.

Le jugement doit être rigoureusement caractérisé

dans son existence.

(P. Valéry)

1 In 1938, in his book Logic: the Theory of Inquiry, John Dewey (1859-1952) established legal judgment as a model for the understanding of judgment in general. The aim of this paper is to consider three theses applying to legal judgment and see if they can also apply to judgment in general. Should that be the case, then Dewey's idea would be confirmed (at least with relation to such theses); should it not be the case, Dewey's idea would be falsified.

2 By "legal judgment" we shall mean the verdict deciding a legal case (including the factual and normative reasons for making it). Then, from a philosophical point of view, the three theses will be discussed with reference to some ideas by Charles S. Peirce (1839-1914) and within a pragmatist framework, insofar as Dewey embraced it. More specifically, this paper will focus on Peirce's theory of inference, scientific method, judgment and assertion. Our conclusion on Dewey's hypothesis will be an affirmative one and, finally, a complex conception of judgment, accounting for both its social and psychological dimensions, will be suggested.

3 On the topic of judgment we must first register a prolonged and widespread philosophical silence; indeed, it is undeniable that judgment plays a marginal role in the philosophy of 
the 20th century. ${ }^{1}$ However, because of its indisputable relevance for both a philosophical and a juridical point of view, we propose to address the subject from both perspectives, in the hope that the merits of the one will not be annulled by the shortcomings of the other.

To start with, a distinction should be made between the following three different conceptions of judgment:

5 (A) Judgment as a mental act attributing a predicate to a subject

(B) Judgment as an act of assent to a proposition

(C) Judgment as a process leading to a proposition.

6 The first is, broadly speaking, the traditional conception that can be found in Peirce's early thoughts; the second one is expounded in his later writings and, in a sense, by Frege too; the third one is considered, among others, by Dewey. The three theses will be based on these three conceptions. The purpose of a judgment is to determine the connotation of a subject or, in other words, to describe a given entity: this is (A), the ontological thesis. Judgment approves the formed proposition, acknowledging it as true: this is (B), the alethic thesis. The proposition is not formed immediately, it develops through a process: this is (C), what will be called genetic thesis. The first two concern, so to speak, the nature of judgment, while the third pertains to its dynamics.

7 Now, it needs to be established whether these theses truly apply to legal judgment and whether they can contribute to an understanding of judgment in general. If that were the case, Dewey's hypothesis would be confirmed. Yet, a number of philosophical issues need to be addressed before answering these questions.

8 It should first be acknowledged that the three conceptions and the relative theses are not in contradiction with one another. In fact, it can be argued that their conjunction actually accounts for what a judgment is. Additionally, their conjunction also accounts for two interesting relations: the one between judgment and inference and the other between judgment and assertion.

9 As to the relation between judgment and inference, judgment in the sense of (A), though fundamental from a conceptual point of view, does not account for the inferential, normative and social dimensions of judgment and of legal judgment in particular. Per se, (A) does not require making explicit the inferences underlying a judgment and justifying it. Conversely, with respect to legal judgment, the rule of law requires judges to make explicit what reasons and inferences justify in their view a decision (i.e. the various factual and normative considerations from which judgment is derived through argumentation). In this sense the first conception of judgment is too narrow to account for both the intersubjective practices underlying judgment (at least in the judicial arena) and the social practices where the premises of judgment need to be clarified to ensure their controllability and the judger's responsibility. The very concept of responsibility, in particular, calls for a recognition of the social dimension judgment is involved in. The same applies to conception (B), which must be integrated with an account of the process forming the proposition being judged. It would seem therefore that only a thesis based on conception (C) is capable of accounting for all this complex dynamics, although it is not yet proven that a genetic thesis can account for the normative dimension of judgment. It may very well be that certain aspects investigated by (C) belong to a level which is very different from that of a normative theory of judgment and of the logical constraints raised by (A) and (B). On the other hand, that would substantiate that it is the conjunction of the three theses that accounts for judgment as a whole and for the relation between 
judgment and inference. To put it differently, only the conjunction of the three provides a full understanding of judgment, given that $(\mathrm{A})$ and $(\mathrm{B})$ do not take into account the ways in which judgment is formed.

10 As for the relation between judgment and assertion, there is clearly the need for a broad conception of judgment, of the (C) type, in order to account for the responsibility implied by an assertion. According to many authors, Peirce included, proposition and belief are not acts. On the contrary judgment and assertion belong to the category of acts, the difference between them being that the former is, so to speak, an internal act, while the latter is an external one. ${ }^{2}$ We will try to show that this characterization does not sufficiently consider judgments in their public form and does not account for the responsibility of assertion. From the genetic viewpoint, we shall suggest a conception of judgment articulating it in three key and logically distinct stages: hypothesis, inquiry, and result. In a certain way, this articulation is a translation of the nature of legal judgment as a process, where the formation of the subject-matter is followed by a testing stage and finally by decision. Moreover, this is the development of a metaphor put forward by Peirce in 1908 (CP 5.546): judgment is a ripening process. Clearly, it is only the evaluation of the process preceding it that makes it possible to assess the responsibility of an assertion. In fact, this way of characterizing (C) is compatible with the logical constraints implied by (A) and (B). Consequently, the conjunction of the three theses and conceptions appears to have the further capacity of accounting for the relation between judgment and assertion too.

11 However, before dealing with their consequences and implications (which look promising so far), it needs to be established whether the three theses are actually true of legal judgment and of judgment in general as well.

\section{The Ontological Thesis}

12 The ontological thesis is about the content of a judgment act. In a certain sense judgment is the attribution of a predicate to a subject (rather than of a subject to a predicate). ${ }^{3}$ In other words, judgment determines the connotation of a subject rather than the denotation of a predicate. Albeit almost irrelevant from a logical perspective, the difference in emphasis is quite relevant to a theory of judgment. From an ontological perspective, judgment is about an object with a certain attribute, not about an attribute exemplified by a certain object. (In semiotic terms, this is an indexical thesis on judgment). Judgment is about something specific, hic et nunc. Peirce conceives of judgment as a mental act by a subject who realizes to have a certain belief, but he also states (chiefly in his early writings, around 1870) that the content of belief consists, in propositional terms, in a predicate associated to a subject, and, in semiotic terms (as he claims around 1885) in an icon associated to an index. ${ }^{4}$ The indexical dimension consists in the fact that the object of judgment can be indicated and shown. The ontological thesis (OT) can therefore be formulated as follows:

(OT) Judgment attributes a property to an object of judgment

(where "attributes" is to be understood broadly, as including both the ascription and the acknowledgment of a property).

This thesis is certainly true of legal judgment, which does not follow (at least not directly) from a question like 
(i) Which subjects exemplify the liability for a theft?

but rather from a question like

(ii) Is Narses liable for this theft?

The purport of OT is lessened by the fact that our judgments are usually related to entities of which we already know certain aspects and must determine an additional property. In these instances the object of judgment is not completely devoid of connotation - on the contrary, all is known about it determines its connotation (or better, determines the connotation of the term designating such object). This observation, however, does not undermine the heart of OT in any way, that is to say the thesis whereby every judgment is matched by an object of judgment with reference to which a property must be determined.

But the following objection might be raised: some types of judgment do not possess an indexical dimension. If certain legal judgments like

(a) Narses is liable for this theft

(b) Narses is not liable for this theft

possess a clear-cut indexical dimension, others do not. For instance, moral judgments like (c) Slavery is bad

draw their strength from their generality. They attribute a predicate to a subject without being indexical judgments. The indexical thesis does not apply to them. OT instead seems to do so if we admit that not only specific entities (the theft involving Narses) but also general entities (slavery) may constitute the object of a judgment. Of course, the type of entity needs to be specified, but it can be admitted that such entities require some form of reality for the moral judgment associated to them not to be totally meaningless. ${ }^{5}$ On the other hand, in addition to such non-indexical moral judgments, there are examples of judgments that are both moral and indexical, for instance

(d) Theodore is generous.

18 Here OT also applies in its indexical dimension. ${ }^{6}$

19 But this implies a further and even stronger objection to OT: if the object of judgment is an entity whatsoever (general or particular, abstract or concrete), ОT looses much of its interest as a thesis. It runs the risk of turning into the tautology whereby every proposition has a subject. Let's consider esthetic judgments like

(e) Le bateau ivre is the most beautiful poem by Rimbaud

(f) I tre filosofi by Giorgione is an amazing painting

or a political judgment like

(g) The relations between North Korea and South Korea are very difficult.

Can it be argued that (e)-(g) judgments concern an object of judgment to the same extent as (a) or (d)? Can we argue that the same ontological thesis applies to (a)-(g) judgments, i.e. that every judgment qualifies an object of judgment? Yes, in a trivial sense it seems to depend on the linguistic structure of judgments; but if we want OT to be interesting, then we must specify the type of object we are dealing with. One may plausibly state that it relates to a variety of entities - some individuals in (a) and (d), a universal in (c), some works of art in (e) and (f), and some institutional entities in (g) - but the question remains whether this thesis is truly an ontological one, namely a thesis about really existing things. Here the alternative runs the risk of being the following one: saying that OT, at least in the formulation herein, applies to judgment in general is tantamount to uttering either a platitude or something false. 


\section{The Alethic Thesis} Susan Haack has recently put it (2007: 14), "factual truth is an essential element of substantive justice; it really matters that the person who is punished be the person who actually committed the crime or caused the injury." Truth is a necessary condition of justice and legal judgments claim to be true. ${ }^{7}$

So the ontological thesis ties on a second thesis about the relation between judgment and truth. It may be called alethic. This thesis considers judgment as the attribution of a truth value to a proposition. In this sense judgment is expressed by assertions like

(a) Narses is liable for this theft.

We have called ontological the aspect of judgment whereby an entity designated by a propositional subject receives its connotation through a predicate. Concept predication is capable of being either true or false and it is for this reason that we call it alethic thesis. As Peirce argued in 1908, judgment is the effort to attain the acquisition of a truth, since in judging that (a), for instance, the formed proposition is deemed true and approved as such, accepting the various consequences thereof, including those related to conduct and responsibility:

even in solitary meditation every judgment is an effort to press home, upon the self of the immediate future and of the general future, some truth. It is a genuine assertion, just as the vernacular phrase represents it; and solitary dialectic is still of the nature of dialogue. Consequently it must be equally true that here too there is contained an element of assuming responsibility, of "taking the consequences" (CP 5.546).

Such an "effort" arises from a conjectural predication seeking confirmation or disproval. It should be noted that, in Peirce's view, a concept constitutive of a proposition makes its appearance in the judgment before the proposition is approved: "the concept makes its appearance before the judgment is ripe, when it is still in the problematic or interrogatory mood" (CP 5.547).

The concept is initially predicated "in the problematic or interrogatory mood" and only at a later stage, if the initial conjecture is confirmed, it may become the content of a justified assertion. This dynamic process starts therefore with a conjectural stage, followed by an inquiry (mental or empirical, depending on the circumstances) and ends with a result susceptible of being the content of an assertion. These observations provide sufficient ground to consider a third thesis on the process of judgment, but before coming to it, the significance and terms of this second thesis must be further specified.

The alethic thesis definitely applies to legal judgment that aims at establishing the truth of (a) or (b), and equally to judgments like (c)-(g) implying a claim of truth regarding their content. ${ }^{8}$ It can be argued that every judgment, regardless of the type, makes a claim of truth about its content and that the alethic thesis (AT) applies to any type of judgment, and consequently to judgment in general too. It may be reformulated as follows:

(AT) Judgment attributes a truth value to a proposition.

(where "attributes" is to be understood again in a broad sense, even though it alludes here to recognition or acknowledgment rather than to ascription.) 
29 As previously stated, OT and AT stem from two different philosophical conceptions of judgment, that can be articulated as follows. For (A) judgment is the attribution of a predicate to a subject. For (B) it is the attribution of a truth value to a proposition (or thought, or belief according to different philosophical standpoints). According to the former and more traditional conception, judgment consists in an association or separation of ideas. ${ }^{9}$ (Saying that it is a predicate associated with a subject makes it definitely more precise). The latter conception was expounded by Gottlob Frege (1848-1925). According to the German philosopher (1879: 52 ff.) judgment is the act through which the truth of a thought is recognized. The proposition "If Narses has committed a theft, then he must be punished" is not strictly speaking a judgment. Judging is the act of approving a proposition, or better, the act recognizing the truth value of the thought expressed by the proposition. Frege, however, takes it a step further. Albeit he does not consider it literally a definition, in 1892 he writes that judgment can be regarded as an advance from a thought to its truth value. ${ }^{10}$ In 1918-19, in his Thought: a Logical Investigation, he draws a distinction between (1) the apprehension of a thought thinking; (2) the recognition of the truth of a thought - judgment; (3) the manifestation of this thought - assertion. ${ }^{11}$ Despite the important differences between the two philosophers (in metaphysics, in particular, Frege is a Platonist while Peirce is a Scotist), Frege's distinctions somewhat resemble the dynamics hinted at by Peirce when he refers to an effort to acquire a truth capable of being asserted.

Moreover, these observations can be usefully compared with some of Dewey's ideas. In 1912 he discriminates between a broad and a narrow sense of the term "judgment."

This term is employed in a larger and more vital sense and in a narrower and more formal one. In its pregnant sense it means the act (or the power) of weighing facts or evidence, in order to reach a conclusion or decision; or (as is usual with words denoting acts) the result, the outcome of the process, the decision reached by the process of reflective inquiry and deliberation (MW 7: 262).

In its narrower and more technical sense a judgment is a statement of a relation between two objects, or between two contents of thought, two meanings (MW 7: 264).

Dewey's narrow and formal sense of judgment resembles judgment in sense (A), and since (A) is the association of a predicate and a subject, it generates a judgment in sense (B), that is, an act of assent to a proposition. It should also be noted that judgment in its "broad and vital" sense overlaps with conception (C): on the one hand, as a process characterized by a plurality of moments and, on the other, as the conclusion of the process. (Dewey will come back to these thoughts in 1938). As the genetic thesis will exemplify, this can be articulated as follows: it is a process starting with a hypothesis on the object of judgment, which continues through a proper investigation and ends with the settlement of what is true about the object of judgment and the consequences of it. ${ }^{12}$

To sum up, Frege refers to an advance; Pierce suggests to use the word effort; Dewey talks about a vital sense of judgment. These are different metaphors by different philosophers. Nonetheless, they show that judgment is not something that one gets in one shot, so to speak; it is a complex phenomenon and is formed by a process. ${ }^{13}$ 


\section{The Genetic Thesis} scientific inquiry expounded by Peirce in 1877 and then modulated in inferential terms after $1900 .{ }^{16}$ The genetic thesis, however, is mainly related to Dewey's considerations on the relation between judgment in general and legal judgment. In Dewey's Logic: the Theory of Inquiry (1938), as we said at the beginning, legal judgment is a model for the understanding of judgment in general. Legal judgment is defined by the three following aspects, deemed of fundamental importance by Dewey (LW 12: 123-5):

1) there is an initial uncertainty and a dispute on what has taken place or on its meaning; 17

2) the dispute is settled through an inquiry and evaluation of the elements produced by the parties involved: evidence is produced about the relevant facts ${ }^{18}$ together with the relevant conceptual considerations, rules and principles which are in force in the legal system; ${ }^{19}$

3) the final judgment determines the legal consequences of the case. ${ }^{20}$

41 Dewey deems these features true of judgment in general. According to his third point, in fact, the final judgment determines the legal consequences of the factual qualification and reconstruction, whereas, to come back to our theses, according to the third moment of 
GT, judgment determines the truth of a proposition. There is undoubtedly a difference, but neither a tension nor a contradiction, since the propositional nature of the final judgment implies the consequences of the judged proposition (in compliance with the pragmatist principle of significance, enunciated by Peirce's pragmatic maxim ${ }^{21}$ ). The genetic thesis will be better appreciated once related to the other theses on judgment. As we saw, there is indeed a close connection between OT and AT on the one hand and the (A) and (B) conception of judgment on the other. According to conception (A), judgment is the attribution of a predicate to a subject. According to conception (B) it is the act of assent to the formed proposition. For OT judgment is the determination of the connotation of a propositional subject. For AT it is the attribution of a truth value to the formed proposition. How are these two theses articulated? They are articulated in the terms of GT and the (C) conception of judgment, i.e. the thesis referring to judgment as a ripening process, from a interrogatory and conjectural stage to a final assertive one, through an inquiry, be it empirical or mental, simple or complex, short or long, according to the object of judgment. Moreover, this way of specifying (C) complies with the logical constraints implied by (A) and (B).

It goes without saying that GT is valid for legal judgment. The question is whether it is equally valid for judgment in general. Does the dynamics highlighted by GT apply to all types of judgment? Or does it only apply to judgments needing an inquiry or a particularly complex reflection? With immediate judgments (for instance perceptual judgments), it would be plausible to consider GT as false. But Peirce argues that a perceptual judgment possesses an inferential character, despite the immediate, neither inferential nor propositional, character of a percept. ${ }^{22}$ In short, the genetic thesis does not apply to immediate judgments, but it is highly uncertain whether something of that kind exists beyond the most elementary perceptual judgments.

Furthermore, Peirce emphasizes that judgments are distinctive of beings endowed with self-control skills (cf. CP 5.115, 5.133, 5.533). As such, judging subjects are responsible for their own judgments. GT is particularly relevant in this respect: the possibility to elucidate the dynamics of judgment involves the possibility to elucidate the reasons of judgment (if this dynamics falls within the scope of self-control, of course). On what grounds has the truth of (a) or (b) been established? What evidence, what inquiry processes, what considerations led to judging Narses guilty? On the contrary, immediate judgments do not imply any responsibility, if it is true that some judgments are formed outside the dimension of self-control. In this sense, GT can cover the normative aspects of judging.

Summing up: OT and AT account for the nature of judgment, GT accounts for its dynamic aspect (in compliance with the logical constraints implied by the two theses on the nature of judgment). According to OT, judging presupposes an object of judgment and the nature of judgment consists in the attribution of a certain property to the object. In a certain way, one might claim that every judgment is provoked by an object that requires a qualification.

This also reveals that judgment is founded, on the one hand, on the ontological status of the object and, on the other, on the cognitive and evaluative components of the qualification. According to AT, judgment consists in the attribution of a truth value to the proposition predicating a certain property of the object of judgment. Thus, OT and AT find a confirmation in the dynamic process pointed out by GT: the ontological thesis specifically concerns the first moment in the judging process, that is to say, the 
hypothetical attribution of a predicate to a subject, whereas the alethic thesis concerns the last moment, that is the determination of the truth value of the hypothesis.

Having said this, how can it be related to Dewey's idea of legal judgment as a model of judgment in general? More specifically, how can Dewey's hypothesis be confirmed with respect to the issues raised about OT? Let us consider the three theses once again:

(OT) Judgment attributes a property to an object of judgment

(AT) Judgment attributes a truth value to a proposition

(GT) Judgment is a process whose result is the attribution of a truth value.

Apparently AT and GT do not raise any particular issues: AT is not in contradiction with Dewey's idea and GT, in particular, meets with his theses on judgment. The problem remains with OT. We have already established that it is either trivial or wrong to say that OT - at least in the current formulation - applies to judgment in general; as a consequence, also Dewey's hypothesis, at least with respect to this thesis, is equally trivial or wrong. On the other hand, at least for the purpose of a conceptual analysis - a trivial truth is preferable to a falsity: let us then take OT as a trivial truth (or, let us take it in the sense that from a logical point of view necessarily a judgment has a propositional subject that designates an object). It should be recalled at this point that it is the conjunction of the three theses that accounts for judgment. Then the question is: does the triviality of OT imply the triviality of the conjunction of the three theses? The answer is a negative one. Even if OT is trivially true of judgment in general, the conjunction of the three theses is not necessarily trivial. This is confirmed a posteriori if we consider the details and implications of AT and GT with relation to the ontological thesis.

Dewey's hypothesis is thus confirmed and it can be concluded that the conjunction of the three theses holds true for judgment in general, and does so in a non trivial way. ${ }_{.}^{23}$ Indeed, this conjunction has some important consequences for a theory of judgment. For instance, it accounts for the relations between judgment, inference and assertion. These relations raise the more general question of the social and normative dimension of judgment and it is precisely on this that we would like to develop a final proposal.

The social dimension of judgment consists in the social character of its conceptual contents and in the public dimension of the assertion of its results. Following Wittgenstein ( $\$ 580$ of his Philosophical Investigations) it can be claimed that judgment is an "internal process" requiring "external criteria." It might be added that the semantic conditions of this process are equally "external": the semantic and conceptual content of our judgments is determined by the social practices determining the inferential role of the words and concepts we use. ${ }^{24}$ On an even more straightforward ground, one may observe that its social dimension is determined by the public dimension of the assertion of its results. Because of it having an eminently public character, legal judgment is thus a true model of judgment in general. There is no private law nor private legal judgment in the sense of secrete law or judgment, insofar as the law aims to rule the conduct of its addressees. ${ }^{25}$ Responsibility is associated to this character, on the account of its close relation with the assertive act.

The following question arises then: does assertion belong to the judgment process or not? If judgment in the (B) sense is the act attributing a truth value to judgment formed in the (A) sense, this does not imply the assertion of its content. However, if our assertions were completely separated from the rest, the assertion of a content, per se, irrespective of the process leading to it and its underlying reasons, would raise issues of responsibility very hard to evaluate. How to evaluate the responsibility of an assertion without knowing 
what process it originates from? There is agreement on one point - assertion is an act entailing responsibility with relation to the interlocutors of the speaker ${ }^{26}$ - but the question remains about the criteria to evaluate such a responsibility. An assertive act, in and of itself, is not sufficient for the purpose of that evaluation. Sure enough, in our practice, our evaluations are not limited to assertions only but embrace the processes leading or expected to lead to them.

Hence, with due consideration for the social dimension of our judgments, the suggestion is to consider assertion as part of the complex process of judging, and to evaluate its responsibilities with respect to this process. If assertion were separate from the other constitutive parts of judgment, its sense and consequences would be hard to establish. Assertion is the part of judgment that manifests the results of our inquiries or reflections and assumes responsibility for them. In summary, judgment in a complex sense may be articulated as follows:

(a) mental act attributing a predicate to a subject

(b) assenting to (the truth of) a predication

(c) asserting a predication.

These points articulate a complex conception of judgment, encompassing assertion. Following this conception, judgment consists of three fundamental acts (predication, assent, assertion) and epistemically speaking, of three fundamental moments (hypothesis, inquiry, result). This understanding makes it possible to account for its components, its logical constraints and finally its public dimension. The truth claims associated to the conclusions are thus justified and validated.

This does not count as a denial of the psychological dimension of judgment. Judging starts with processes belonging to such a dimension (first of all, the formulation of a hypothesis). But the import of their contents would inevitably remain indeterminate for us if those processes and their results were not to be publicly manifested, compared and evaluated.

\section{BIBLIOGRAPHY}

AARNIO A. \& N. D. MACCORMICK (eds.), (1992), Legal Reasoning, 2 vols., Dartmouth, Aldershot.

BELL D., (1979), Frege's Theory of Judgement, Oxford, Clarendon Press.

BRANDOM R., (1994), Making It Explicit, Cambridge (Mass.) and London, Harvard University Press.

BRANDOM R., (2000), Articulating Reasons, Cambridge (Mass.) and London, Harvard University Press.

BUTLER B.E., (2010), “Democracy and Law: Situating Law within John Dewey’s Democratic Vision," Etica e Politica, XII (1), 256-80.

DAMAŠKA M. R., (1986), The Faces of Justice and State Authority, New Haven and London, Yale University Press.

DANCY J., (1993), Moral Reasons, Oxford, Blackwell. 
DUmmetт M., (2003), “Truth and the Past," The Journal of Philosophy, C, 1, 5-53.

ENGEL P., (1999), “Dispositional Belief, Assent, and Acceptance," Dialectica, 53, 3-4, 211-26.

ESFELD M., (1999), review of Brandom (1994), Erkenntnis 51, 333-46.

FREGA R., (2006), Pensée, expérience, pratique. Étude sur la théorie du jugement de John Dewey, Paris, L'Harmattan.

FREGE G., (1879), “Begriffsschrift,” now in Beaney M. (ed.), The Frege Reader, London, Blackwell, 1997.

FREGE G., (1892), "On Sinn and Bedeutung," now in Beaney M. (ed.), The Frege Reader, London, Blackwell, 1997.

FREGE G., (1918-19), Logical Investigations, now in Beaney M. (ed.), The Frege Reader, London, Blackwell, 1997.

FULLER L. L., (1969), The Morality of Law, New Haven and London, Yale University Press.

HAACK S., (2004), "Truth and Justice, Inquiry and Advocacy, Science and Law," Ratio Juris, 17 (1), $15-26$.

HAACK S., (2007), “On Logic in the Law: 'Something, but not all'," Ratio Juris, 20 (1), 1-31.

ноокWAY C., (1985), Peirce, London, Routledge and Kegan Paul.

HUSSERL E., (1939), Experience and Judgment, trans. by J. Churchill \& K. Ameriks, Evanston, Northwestern University Press, 1973.

MACCORMICK N. D., (1978), Legal Reasoning and Legal Theory, Oxford, Clarendon Press.

MCDOWELL J., (1994), Mind and World, Cambridge (Mass.) and London, Harvard University Press.

PICARDI E., (1997), "Sigwart, Husserl and Frege on Truth and Logic, or Is Psychologism Still a

Threat?," European Journal of Philosophy 5, 162-82.

PUTNAM H., (2004), Ethics without Ontology, Cambridge (Mass.) and London, Harvard University Press.

RAMSEY F. P., (1927-29), On Truth, ed. by N. Rescher \& U. Majer, Dordrecht, Kluwer Academic Publishers, 1991.

RUSSELL B., (1910), Philosophical Essays, London, George Allen \& Unwin, 1984.

SUMMERS R. S., (1999), "Formal Legal Truth and Substantive Truth in Judicial Fact-Finding - Their Justified Divergence in Some Particular Cases," Law and Philosophy 18, 497-511.

TALISSE R. B., (2010), “Saving Pragmatist Democratic Theory (from Itself),” Etica e Politica, XII (1), $12-27$.

TIERCELIN C., (1985), "Logique, psychologie et métaphysique: les fondements du pragmatisme selon C. S. Peirce,” Zeitschrift für Allgemeine Wissenschaftstheorie, XVI (2), 229-50.

TIERCELIN C., (1993), La pensée-signe. Études sur C. S. Peirce, Nîmes, Éditions Jacqueline Chambon. TUZET G., (2003), “L'abduzione percettiva in Peirce,” Aquinas, XLVI (2-3), 307-27.

TUZET G., (2006), “Responsible for Truth? Peirce on Judgment and Assertion,” Cognitio, 7 (2), 317-36.

TUZET G., (2010), Dover decidere. Diritto, incertezza e ragionamento, Roma, Carocci. 
TWINING W., (1991), “Lawyers' Stories,” in Kevelson R. (ed.), Action and Agency, New York, Peter Lang.

Williamson T., (1996), “Knowing and Asserting,” The Philosophical Review, 105 (4), 489-523. WRÓBLEWSKI J., (1992), The Judicial Application of Law, ed. by Z. Bankowski \& N. MacCormick, Dordrecht, Kluwer Academic Publishers.

\section{APPENDIXES}

Abbreviations

$\mathrm{CP}$

Collected Papers of C.S. Peirce, 8 vols., ed. by C. Hartshorne, P. Weiss (vols. 1-6) and A. Burks (vols. 7-8), Harvard University Press, Cambridge (Mass.), 1931-1958. For ex. CP 5.189: vol. 5, par. 189.

LW

The Later Works of J. Dewey, 1925-1953, ed. by J. A. Boydston, Southern Illinois University Press, Carbondale and Edwardsville, 1981-1990. For ex. LW 3: 111: vol. 3, p. 111.

MW

The Middle Works of J. Dewey, 1899-1924, ed. by J. A. Boydston, Southern Illinois University Press, Carbondale and Edwardsville, 1976-1983. For ex. MW 3: 111: vol. 3, p. 111.

NEM

The New Elements of Mathematics by Charles S. Peirce, 4 vols., ed. by C. Eisele, Mouton, The Hague, 1976. For ex. NEM 3: 187: vol. 3, p. 187.

W

Writings of C.S. Peirce: a Chronological Edition, 7 vols. published, ed. by M. Fisch et al., Indiana University Press, Bloomington, 1982-. For ex. W1: 210: vol. 1, p. 210.

\section{NOTES}

1. See however Russell's theory of judgment in the first half of the century, discussed by Wittgenstein and Ramsey among others (cf. Russell 1910: 147-59, Ramsey 1927-29), and see Husserl's later thoughts (1939).

2. "What is the essence of a Judgment? A judgment is the mental act by which the judger seeks to impress upon himself the truth of the proposition. It is much the same as an act of asserting the proposition, or going before a notary and assuming formal responsibility for its truth, except that those acts are intended to affect others, while the judgment is only intended to affect oneself" (CP 2.252). Cf. W4: 164, CP 2.309, CP 8.115, CP 8.337, NEM 4: 39.

3. The articulation of judgment in propositional terms allows Peirce to perform (especially in his early writings) a logical analysis of judgment; cf. Tiercelin (1985: 246 n. 94); see also Tiercelin (1993: chaps. 1 and 4). Cf. W1: 152, W2: 179, CP 5.115.

4. "This act which amounts to such a resolve, is a peculiar act of the will whereby we cause an image, or icon, to be associated, in a particular strenuous way, with an object represented to us by 
an index. This act itself is represented in the proposition by a symbol, and the consciousness of it fulfills the function of a symbol in the judgment" (CP 2.435). Articulating an index with an icon generates, according to Peirce, a symbol, that is a logical and conventional sign that is capable of having a truth value.

5. Dancy's moral particularism (1993) could be easily harmonized with OT, but the question remains whether or not it is a satisfactory theory of moral judgments. See also Putnam (2004: 26-7) commenting on Levinas's moral philosophy: “Levinas's thought experiment is always to imagine myself confronted with one single suffering human being, ignoring for the moment the likelihood that I am already under obligation to many other human beings. I am supposed to feel the obligation to help this human being, an obligation which I am to experience not as the obligation to obey a principle, as a Kantian would, but as an obligation to that human being."

6. If then one might go as far as to argue that non-indexical moral judgments stem from a generalization starting from specific instances, non-indexical moral judgments would rest all the same on an indexical basis. A similar relation applies between the judgments of the lower and higher courts in the legal domain. Cf. Twining (1991: 336) on the importance of concrete cases in a common law perspective.

7. Cf. Summers 1999. But, on the tensions between science and law, see Haack 2004.

8. On the other hand one may wonder what would the truth of (c) and (e) consist of. Are there any moral and esthetic truths? Are there any moral and esthetic facts making (c) and (e) true? Are (c) and (e), instead, expressions of feelings without any truth value? Are they norms, that is ought-judgments instead of is-judgments? One may very well contend, in any case, that there are propositions (true or false) describing moral or esthetic feelings (neither true or false) or describing norms (neither true or false).

9. Cf. in particular Arnauld and Nicole, La logique ou l'art de penser, II. In the contemporary debate cf. McDowell 1994.

10. Frege (1892: 159): "Judgements can be regarded as advances from a thought to a truth-value. Naturally this cannot be a definition. Judgement is something quite peculiar and incomparable."

11. Frege (1918-19: 329). In his second logical investigation (Negation), compare the distinction between (1) grasping a thought, and (2) judging: we can grasp the meaning of an interrogative sentence without knowing its truth value (Frege 1918-19: 347-8). Cf. Bell 1979, Picardi 1997, and Tuzet 2006.

12. "In this sense judgment expresses the very heart of thinking. All thinking is, directly or indirectly, a part of the act of judging, of forming an estimate or valuation after investigation and testing" (MW 7: 262).

13. But see Ramsey (1927-29: 46), who conceives of judging as including any form of "thinking that" independently of the way it is arrived at.

14. See e.g. Damaška 1986. Such parts, while often informal and unreflected in ordinary judgments, are normatively determined in legal judgments structured according to certain procedures.

15. "A judgment is a mental act deliberately exercising a force tending to determine in the mind of the agent a belief in the proposition: to which should perhaps be added that the agent must be aware of his being liable to inconvenience in the event of the proposition's proving false in any practical aspect" (NEM 4: 250).

16. See of 1877 The Fixation of Belief (CP 5.358-387; W3: 242-57). Cf. of 1901 On the Logic of Drawing History from Ancient Documents (CP 7.162-255).

17. "There is uncertainty and dispute about what shall be done because there is a conflict about the significance of what has taken place, even if there is agreement about what has taken place as a matter of fact - which, of course, is not always the case. The judicial settlement is a settlement of an issue because it decides existential conditions in their bearing upon further activities: the 
essence of the significance of any state of facts" (LW 12: 123-4). On Dewey's theory of judgment cf. Frega 2006.

18. "On the one hand, propositions are advanced about the states of facts involved. Witnesses testify to what they have heard and seen; written records are offered, etc. This subject-matter is capable of direct observation and has existential reference. As each party to the discussion produces its evidential material, the latter is intended to point to a determinate decision as a resolution of the as yet undetermined situation. The decision takes effect in a definite existential reconstruction" (LW 12: 124).

19. "On the other hand, there are propositions about conceptual subject-matter; rules of law are adduced to determine the admissibility (relevancy) and the weight of facts offered as evidence. The significance of factual material is fixed by the rules of the existing juridical system; it is not carried by the facts independent of the conceptual structure which interprets them. And yet, the quality of the problematic situation determines which rules of the total system are selected" (LW 12: 124). On Dewey, law and democracy cf. Talisse 2010, and Butler 2010.

20. "The final judgment arrived at is a settlement. The case is disposed of; the disposition takes effect in existential consequences. The sentence or proposition is not an end in itself but a decisive directive of future activities. [...] While prior propositions are means of instituting the sentence, the sentence is terminal as a means of instituting a definite existential situation" (LW 12: 124-5). On legal reasoning see among others MacCormick 1978, Aarnio-MacCormick 1992, Wróblewski 1992, Tuzet 2010.

21. "Consider what effects, that might conceivably have practical bearings, we conceive the object of our conception to have. Then, our conception of these effects is the whole of our conception of the object" (CP 5.402, 1878). Cf. CP 8.33 (1871); W3: 77, 108 (1873); CP 5.432, 5.438 (1905).

22. Cf. Hookway (1985: chap. 5); Tiercelin (1993: chaps. 2-3); Tuzet 2003.

23. Is "confirmed" too strong a term here? I don't think so, if Dewey's hypothesis is found to be true.

24. Cf. Brandom 1994, and 2000; Esfeld 1999.

25. See Fuller (1969: 49-51).

26. See CP 2.314-315, 2.252, CP 5.30, 5.546-548, NEM 4: 39. On knowledge and assertion cf. Williamson 1996. On assertion, acceptance and meaning cf. Dummett (2003: 11): "A theory of meaning given in terms of the grounds for asserting a statement I shall call a justificationist theory; one given in terms of the consequences of accepting a statement I shall call a pragmatist theory." For a distinction between assent and acceptance cf. Engel 1999.

\section{ABSTRACTS}

The article addresses three theses on judgment in general and legal judgment in particular, starting from Peirce's and Dewey's claims about them. The first thesis, ontological, concerns the content of an act of judgment and says that judgment is about an object instantiating a property (not about a property instantiated by an object). The second, alethic, concerns the relation between judgment and truth and says that judgment is the attribution of a truth value to a proposition. The third, genetic, deals with the moments of judgment claiming it is a process susceptible of being articulated in such moments. Its fundamental moments are 1) hypothesis, 2) 
inquiry, 3) result. The article claims that the three theses interconnect and hold for both judgment in general and legal judgment, given that the latter is a model of the former; so a complex conception of judgment is articulated, discussing also its relations with assertion and inference.

\section{AUTHOR}

GIOVANNI TUZET

Bocconi University

giovanni.tuzet[at]unibocconi.it 